\title{
Água utilizada em estabelecimentos que comercializam produtos cárneos, na cidade de Jaboticabal/SP, como via de contaminação dos alimentos
}

\section{Water used in meat-selling shops and food contamination}

\author{
Luiz Augusto do Amaral, ${ }^{*}$ Oswaldo Durival Rossi Júnior, ${ }^{*}$ Antonio Nader Filho, ${ }^{*}$ Fernanda Lucia Alves Ferreira, ${ }^{*}$ \\ Debora Donato Hagi*
}

\begin{abstract}
Resumo
O controle da qualidade da água nos estabelecimentos que manipulam produtos cárneos é de grande importância, pois a carne e seus derivados são excelentes substratos para o desenvolvimento de microrganismos, inclusive os de veiculação hídrica. As amostras de água foram colhidas e transportadas de acordo com APHA (1998). Nas determinações dos Números mais Prováveis (NMP) de coliformes totais e Escherichia coli foi utilizada a técnica do substrato cromogênico e nas contagens de microrganismos heterotróficos mesófilos o ágar PCA (APHA,1998). Nos isolamento de Pseudomonas aeruginosa foi utilizada a técnica de membranas filtrantes utilizando-se M-PA-C ágar (BBL, cat. 298153) e confirmação em ágar leite (APHA,1998) e para o isolamento de Staphylococcus spp foi utilizado ágar Baird Parker (APHA,2001). As concentrações de cloro foram determinadas em colorímetro (HANNA,1997). No período de chuvas $7,5 \%$ e $27,5 \%$ das amostras estavam fora dos padrões de potabilidade, segundo a Portaria $n^{\circ} 518$ do Ministério da Saúde, antes e após a passagem pelo reservatório, respectivamente. No período de estiagem estas porcentagens foram 5,3\% e 23,7\%. No que se refere à presença de Pseudomonas aeruginosa e Staphylococcus spp, as porcentagens de isolamento destes microrganismos foram $7,5 \%$ e $15,0 \%$ e $15,0 \%$ e $20,0 \%$, no período de chuvas, antes e após a passagem pelo reservatório, respectivamente. No período de seca essas porcentagens foram $5,3 \%$ e $0,0 \%$ e $13,1 \%$ e $18,4 \%$, antes e após a passagem pelos reservatórios, respectivamente. Foi verificada também a demanda de cloro após a passagem pelo reservatório que variou de 2,3\% a 96,2 \%. Sob o aspecto de Saúde Coletiva, a água com qualidade higiênico-sanitária insatisfatória, utilizada nos estabelecimentos que manipulam e comercializam produtos cárneos, como é o caso das amostras analisadas na presente pesquisa, pode veicular microrganismos para a carne, que, sendo um excelente meio para o desenvolvimento de diversos microrganismos, pode potencializar a contaminação veiculada, transformando-se em produto de risco à saúde dos consumidores.
\end{abstract}

Palavras-chave: água, açougue, produtos cárneos.

\begin{abstract}
Since meat and meat products harbor the development of microorganisms, including those moved through water, quality control of water used in meat retail outputs is of great importance. Water sample were collected, transported according to APHA (1998). Chromogenic substrate technique was employed to determine the most probably number (NMP) of total coliform bacteria and Escherichia coli, PCA ágar in mesophylic microorganisms counts and Agar M-PA-C (BBL, cat. 298153), corroborated by milk agar, were used to isolate Pseudomonas aeruginosa (APHA,1998) and for the isolation of Staphylococcus spp was used Agar Baird Parker (APHA,2001), whereas chlorine concentrations were determined by chlorine meter (HANNA,1997). During the rainy season, $7.5 \%$ and $27.5 \%$ of water samples, respectively before and after passing through the reservoir, were below drinking standards, according to Health Departament criteria. Percentages were respectively $5.3 \%$ and $23.7 \%$ during the dry season. Isolation percentages of Pseudomonas aeruginosa and Staphylococcus spp were $7.5 \%$ and $15.0 \%$ and $15.0 \%$ and $20.0 \%$ during the rainy season, respectively, prior to and after their passage through the reservoir. During the dry season the percentages reached $5.3 \%$ and $0.0 \%$ and $13.1 \%$ and $18.4 \%$ respectively before and after passing through the reservoir. Chlorine demanded ranged from $2.3 \%$ to $96.2 \%$ after water passage through reservoir. According to Health Department criteria, water used in meat outputs is below hygiene and health standards. As shown by sample analyzed, the water may carry harmful microorganisms to the meat which, being an excellent milieu for bacteria development becomes a health hazard product for consumers.
\end{abstract}

Keywords: water, eat outputs, meat products.

\section{Introdução}

A qualidade da água utilizada na produção e manipulação de alimentos é constantemente negligenciada. Porém, a água de má qualidade microbiológica pode ser uma fonte de microrganismos que tanto podem promover a deterioração dos alimentos como causar enfermidades na população consumidora, caso microrganismos patogênicos estejam presentes.

\footnotetext{
* Faculdade de Ciências Ágrarias e Veterinárias - Unesp - Via de Acesso Prof. Paulo Donato Castellane s/n - CEP: 14884-900 - Jaboticabal-SP. e-mail: lamaral@fcav.unesp.br
} 
De acordo com Hobbs e Roberts (1993), o fornecimento de água potável em abundância é necessário para a indústria de alimentos, uma vez que é importante via de transmissão de agentes patogênicos ao ser humano, tanto pelo seu consumo direto, como pela contaminação de alimentos e do ambiente de preparo dos mesmos. Galbraith et al. (1987), em estudos sobre doenças transmitidas por alimentos, realizados no Reino Unido, verificaram que 1.000 casos de doenças gastrointestinais foram causados por alimentos de origem animal contaminados por água poluída durante o processamento.

O controle da qualidade da água nos estabelecimentos que manipulam produtos cárneos é de grande importância, pois a carne e seus derivados são excelentes substratos para o desenvolvimento de microrganismos, inclusive os de veiculação hídrica. Palumbo et al (1999) inocularam Enterococcus spp, Staphylococcus aureus e Listeria monocytogenes na água utilizada em indústrias de processamento de carne e verificaram a sobrevivência desses microrganismos por 21 dias, enfatizando a importância do controle da qualidade da água na indústria de alimentos.

Segundo Frazier e Westhoff (1978), toda a água que se coloca em contato com o alimento deve cumprir os mesmos padrões microbiológicos da água de consumo humano. Van Hounten et al. (1998) referem-se a um surto de doença de origem alimentar em Livingston, EUA, causado por alimentos contaminados pela água durante sua preparação, sendo isoladas Plesiomonas shigelloides e Salmonella sorotipo Hartford da água e dos alimentos envolvidos.

Diante do exposto e considerando a importância da água em estabelecimentos processadores de alimentos, especialmente na higienização de equipamentos e utensílios, e a importância da água como veículo potencial de microrganismos patogênicos, o presente trabalho foi realizado com o objetivo de verificar o potencial papel da água utilizada em estabelecimentos que comercializam produtos cárneos, na cidade de Jaboticabal/SP, como veículo de microrganismos que possam colocar em risco a saúde da população consumidora desses alimentos.

\section{Material e métodos}

\section{Colheita das amostras (APHA, 1998)}

As amostras de água foram colhidas nos 40 estabelecimentos que comercializam produtos cárneos situados na cidade de Jaboticabal, São Paulo, Brasil, na época de chuvas e de 38 na época de estiagem.

Todas as amostras foram colhidas em frascos esterilizados com capacidade de $250 \mathrm{~mL}$ na entrada dos estabelecimentos e no ponto de uso, após passagem da água pelo reservatório, e acondicionadas em caixa de material isotérmico contendo cubos de gelo.

Quantificação de coliformes totais e Escherichia coli pelo sistema de utilização de substrato cromogênico (APHA, 1998)

O meio de cultura (COLILERT) foi adicionado na amostra de água $(100 \mathrm{~mL})$ e após homogeneização, a mistura foi trans- ferida para cartela Quanti-tray e selada em seladora específica. Em seguida, as cartelas foram incubadas a $35^{\circ} \mathrm{C}$ por 24 horas. A seguir, foi realizada a determinação do Número Mais Provável (NMP) de coliformes totais através da contagem das células com coloração amarela e utilização de tabela própria. O NMP de Escherichia coli foi determinado pela contagem do número de células que apresentaram fluorescência após a incidência de raios UV, comprimento de onda $365 \mathrm{~nm}$, sobre a cartela, utilizando-se a mesma tabela para coliformes totais.

\section{Contagem de microrganismos heterotróficos mesófilos (APHA, 1998)}

Para a realização das contagens de microrganismos mesófilos $1,0 \mathrm{~mL}$ da amostra e de suas diluições decimais foram depositados, em duplicata, em placas de Petri esterilizadas, às quais foram adicionados cerca de $15 \mathrm{~mL}$ de ágar padrão para contagem previamente fundido e resfriado até a temperatura em torno de $45^{\circ} \mathrm{C}$. Após a homogeneização e solidificação, em temperatura ambiente, as placas foram incubadas a $35^{\circ} \mathrm{C}$ por 48 horas. As contagens foram realizadas em aparelho apropriado, sendo utilizadas as placas que apresentavam entre 25 e 250 colônias. A média do número de colônias contadas nas placas em duplicata, multiplicada pelo fator de diluição correspondente, expressou o número de microrganismos mesófilos por $\mathrm{mL}$ da amostra.

\section{Contagem de Pseudomonas aeruginosa (APHA, 1998)}

As contagens de Pseudomonas aeruginosa foram realizadas a partir de volumes de $100 \mathrm{~mL}$ de cada amostra de água filtrados através de um aparelho de filtração contendo membranas filtrantes com porosidade $0,45 \mathrm{~mm}$.

No teste presuntivo, após a filtração a membrana foi colocada em placa de Petri contendo Ágar M - PA - C (BBL, cat. 298153), invertendo-se as placas em seguida e incubando a 41,5 \pm $0,5^{\circ} \mathrm{C}$ durante 72 horas. Após a incubação, com auxílio de contador de colônias, foram contadas as colônias com 0,8 a 2,2 mm de diâmetro, achatadas com bordas claras e o centro de verde a marrom escuro. No teste para confirmação foi usada a semeadura em ágar leite. A incubação foi conduzida a $35 \pm$ $1,0^{\circ} \mathrm{C}$ durante 24 horas e considerou-se Pseudomonas aeruginosa quando ocorreu a produção de pigmento amarelo esverdeado.

\section{Isolamento de Staphylococcus spp (APHA, 2001)}

Volumes de $100 \mathrm{~mL}$ das amostras de água e suas diluições decimais foram filtradas em membrana $0,45 \mathrm{~mm}$ e as membranas transferidas para placas de Petri, contendo Ágar Baird Parker. Os microrganismos que formaram colônias características do gênero Staphylococcus, ou sejam, negras brilhantes, foram corados pelo método de Gram. As colônias que se apresentaram com microrganismos em forma de cocos, agrupados em cachos e Gram+, foram submetidas aos testes da catalase e OF/Glicose (Mac Faddin, 1976).

\section{Determinação dos teores de Cloro (HANNA, 1997)}

Os teores de cloro nas amostras de água foram determinados em colorímetro modelo HI93701. 


\section{Análise estatística (Stell \& Torrie, 1960)}

Foi realizado o teste do Qui-quadrado para verificar a significância da diferença entre os números de amostras de água da entrada dos estabelecimentos e dos reservatórios que estavam fora dos padrões microbiológicos de potabilidade nos períodos de chuva e estiagem.

\section{Resultados e discussão}

Na Tabela 1 são apresentados os números e as porcentagens de amostras de água colhidas na entrada dos estabelecimentos e após passagem pelo reservatório dentro e fora dos padrões microbiológicos de potabilidade, segundo o Número Mais Provável de Escherichia coli e o número de microrganismos mesófilos (BRASIL, 2004).

Observa-se na Tabela 1 que as porcentagens de amostras fora dos padrões microbiológicos de potabilidade colhidas após passagem pelos reservatórios são superiores àquelas colhidas na entrada dos estabelecimentos $(p<0,05)$.

Sob o aspecto de saúde coletiva, a água com qualidade higiênico-sanitária insatisfatória ao ser utilizada nos estabelecimentos que manipulam e comercializam produtos cárneos, como é o caso das amostras que se apresentaram fora dos padrões de potabilidade, pode veicular microrganismos à carne, que, sendo um excelente meio para o desenvolvimento de diversos microrganismos, pode potencializar a contaminação veiculada, transformando-se em um

Tabela 1: Número e porcentagens de amostras de água colhidas na entrada dos estabelecimentos e após passagem pelo reservatório, no período das chuvas e de estiagem, dentro e fora dos padrões microbiológicos de potabilidade ( Brasil 2004)

\begin{tabular}{c|c|c|c|c|c}
\hline \multirow{2}{*}{ Amostra } & \multirow{2}{*}{ Período } & \multicolumn{2}{|c}{ Dentro dos Padrões } & \multicolumn{2}{c}{ Fora dos Padrões } \\
\cline { 3 - 6 } & & no & $\%$ & no & $\%$ \\
\hline \multirow{2}{*}{ Entrada do estabelecimento } & Chuvas $^{\mathrm{A}}$ & 37 & 92,5 & 3 & 7,5 \\
& Estiagem $^{\mathrm{A}}$ & 36 & 94,7 & 2 & 5,3 \\
\hline Após passagem pelo & Chuvas $^{\mathrm{B}}$ & 29 & 72,5 & 11 & 27,5 \\
reservatório & Estiagem $^{\mathrm{B}}$ & 29 & 76,3 & 9 & 23,7 \\
\hline
\end{tabular}

Na mesma coluna letras maiúsculas diferentes, no mesmo período, diferem entre si ao nível de $5 \%$ de probabilidade.

Tabela 2: Número e porcentagens de amostras de água colhidas na entrada dos estabelecimentos e após passagem pelo reservatório, com isolamento positivo de Pseudomonas aeruginosa e Staphylococcus spp no período das chuvas e de estiagem

\begin{tabular}{c|c|c|c|c|c}
\hline \multirow{2}{*}{ Amostra } & \multirow{2}{*}{ Período } & \multicolumn{2}{|c|}{ P. aeruginosa } & \multicolumn{2}{c}{ Staphylococcus spp. } \\
\cline { 3 - 6 } & & $\mathbf{n} \mathbf{0}$ & $\%$ & $\mathbf{n}$ - & $\%$ \\
\hline $\begin{array}{c}\text { Entrada do } \\
\text { estabelecimento }\end{array}$ & Chuvas & 3 & 7,5 & 6 & 15,0 \\
\hline \multirow{2}{*}{$\begin{array}{c}\text { Estiagem } \\
\text { Após passagem pelo } \\
\text { reservatório }\end{array}$} & Chuvas & 6 & 5,3 & 5 & 13,1 \\
\hline
\end{tabular}

produto de risco à saúde dos consumidores. A esse respeito braith et al. (1987) em estudos sobre doenças transque 1.000 casos de doenças gastrointestinais foram cor alimentos de origem animal contaminados por Deve-se destacar a alteração na qualidade da água após passagem pelos reservatórios, no período de chuvas e de estiagem, em decorrência da falta de limpeza periódica dos reservatórios. Essa queda na qualidade da água foi verificada por Genthe et al. (1987), que observaram significativa redução qualidade microbiológica da água após sua captação, pois reservatório, apresentou elevação nos níveis de microrganismos indicadores e Lindskog e Lindskog (1988) que verificanas contaminações das águas.

Tabela 2 são apresentadas as porcentagens e o número Pseudomonas aeruginosa e Staphylococcus spp, no período de chuvas e de estiagem.

$\mathrm{O}$ isolamento de Pseudomonas aeruginosa nas amostras de água colhidas nos estabelecimentos que comercializam carne produtos cárneos tem grande importância, uma vez que esponsáveis pela deterioração dos alimentos, diminuindo seu prazo de vida comercial (Madeira et al., 1997). Além da deterioração dos alimentos, a presença deste microrganismo na água é importante, pois além de ser deteriorante e indicadora de contaminação, é também um patógeno oportunista que freqüentemente está envolvido com infecções que variam em local e severidade: desde infecções superficiais como foliculites e piodermites a pneumonia em pacientes com pneumopatia crônica expostos a aerosóis contendo água contaminada (Rosenberg, 1990).

A presença de Staphylococcus spp na água dos estabelecimentos é importante sob o aspecto de saúde coletiva pois, uma vez chegando aos produtos cárneos e existindo condição de temperatura e a presença de staphylococcus aureus, produtores de 
enterotoxinas, esses microrganismos podem se multiplicar e atingir números que produzem uma quantidade de toxina capaz de causar intoxicação. Ressalta-se que a toxina estafilocócica é termorresistente, não sendo inativada durante o processamento do alimento, causando severos casos de gastroenterites em crianças e idosos (Melchíades et al., 1993). Depreende-se, portanto, que água pode veicular esses microrganismos para a carne e produtos cárneos que podem chegar ao consumidor já com enterotoxina termorresistente persistindo no produto mesmo após o tratamento térmico antes do consumo.

Na Tabela 3 são apresentados demanda média de cloro na água causada pela reservação da água e o valor porcentual mínimo e máximo de cloro nas amostras de água colhidas nos períodos de chuvas e de estiagem.

Com relação à demanda de cloro, observa-se que a demanda média no período de chuvas e de estiagem variou de 39,7 a

Tabela 3: Valor porcentual mínimo, médio e máximo das demandas de cloro obtidas nas amostras de água colhidas nos estabelecimentos que comercializam produtos cárneos na cidade de Jaboticabal, SP

\begin{tabular}{ccc}
\hline Demanda de cloro & Período & $(\%)$ \\
\hline \multirow{2}{*}{ MÍNIMA } & Chuvas & 2,3 \\
& Estiagem & 11,5 \\
\hline \multirow{2}{*}{ MÉDIA } & Chuvas & 39,6 \\
& Estiagem & 35,7 \\
\hline \multirow{2}{*}{ MÁXIMA } & Chuvas & 96,2 \\
& Estiagem & 73,8 \\
\hline
\end{tabular}

$35,7 \%$. Além disso, deve-se destacar que a demanda máxima no período chuvoso atingiu uma porcentagem de 96,2\% (Tabela 3), indicando a falta de limpeza dos reservatórios.

Verifica-se, portanto, que a demanda de cloro dos reservatórios faz com que, durante a permanência da água, possa ocorrer a sobrevivência e multiplicação de microrganismos aumentando o número de amostras fora dos padrões microbiológicos de potabilidade, o que potencializa a ação da água utilizada nos estabelecimentos como fator de risco para a qualidade do alimento comercializado.

\section{Conclusões}

1 - Amostras de água fora dos padrões de potabilidade foram verificadas na água da entrada dos estabelecimentos e após a passagem pelos reservatórios, evidenciando o risco que a água pode representar para a qualidade dos produtos comercializados.

2 - O isolamento de Pseudomonas aeruginosa e Staphylococcus spp. nas amostras de água colhidas antes e após a passagem pelos reservatórios é uma verificação importante no que se refere aos riscos que essas águas podem apresentar à saúde dos consumidores e também à qualidade dos produtos cárneos manipulados nos estabelecimentos.

3 - Deve-se realizar um trabalho de orientação aos comerciantes, principalmente no que se refere à limpeza e higiene dos reservatórios, no sentido de evitar que a água dos estabelecimentos atue como via de transmissão de agentes patogênicos e deteriorantes para a carne e produtos cárneos comercializados.

\section{Agradecimento}

Os autores agradecem à Fundação de Amparo à Pesquisa do Estado de São Paulo - FAPESP pelo financiamento da presente pesquisa e pela bolsa de Iniciação Científica.

\section{Referências}

AMERICAN PUBLIC HEALTHASSOCIATION (APHA). Standardmethods for the examination of water and wastewater, AWWA, $20^{\text {th }}, 1998$.

AMERICAN PUBLIC HEALTH ASSOCIATION - APHA. Compendium for the microbiological examination of foods. 4. ed. Washington: APHA, $2001.696 \mathrm{p}$.

BRASIL. MINISTÉRIO DA SAÚDE. Portaria n. 518 de 25 de março de 2004. Procedimentos e responsabilidades relativos ao controle e vigilância da qualidade da água para consumo humano e seu padrão de potabilidade. Diário Oficial da República Federativa do Brasil, Poder Executivo, Brasília, DF, 26 mar. 2004.

FRAZIER, W. C; WESTHOFF, D. C. Microbiología de los alimentos. Ed. Acribia, Zaragoza, Espanha, 1978.523 p.

GALBRAITH, N.S.; BARRET, N.J.; STANWELL-SMITH, R. Water and disease after Croydon: A review of water-borne and water-associated disease in the UK 1937-1986. Journal Institute of Water \& Environment Management, n. 1, p. 7-21, 1987.

GENTHE, B.; STRAUSS, N.; SEAGER, J.; VUNDULE, C.; HAFORAH, F.; $K F I R, R$. The effect of type water supply on water quality in a developing community in South Africa. Water Science and Technology, v. 35, n. 11, p. 35-40, 1997.

HOBBS, B. C.; ROBERTS, D. Toxiinfecções e controle higiênicosanitário de alimentos. São Paulo: Ed Varella, 1993. 376 p.
LINDISKOG, R.; LINDSKOG, P.A. Bacteriological contamination of water in rural areas: an intervention study from Malawi. Journal of Tropical Medicine and Hygiene, v. 91, n. 1, p. 1-7, 1988.

Mac FADIN, J.F. Biochemical tests for identification of medical bacteria. Baltimore: Williams \& Wilkins, 1976.

MADEIRA, R.O.; MORON, C.; BUCHBINDER, B.; GONZALEZ, O.; RESBANI, J.C. Potabilización de aguas - estudio de las distintas alternativas. In: Seminario regional de calidad de leche, Argentina. Anais, p.173-182, 1997.

MELCHÍADES, L.E.A.; VEIGA, V.M.O.; RIBEIRO, M.T.; DUTRA, I.S. Produção de enterotoxinas por Staphylococcus isolados de mastite subclínica bovina. Revista do Instituto de Laticínios Cândido Tostes, v. 48, n. 288, p. $80-81,1993$.

PALUMBO, S. A.; PICKARD, A.; CALL, J. E. Fate of gram-positive bacteria in reconditioned pork processing plant water. Journal of Food Protection, v. 62, n. 2, p. 194-197, 1999.

ROSENBERG, F.A. The bacterial flora of natural mineral waters and potential problems associated with its ingestion. Rivista Italiana d'lgiene, v. 62, n. 2, p. 194-197, 1999.

STEEL, R.G.D.; TORRIE, J.H. Principles and procedures of statistics. New York, Mc Graw, 1960, 481 p.

VANHOUTEN, R.;FARBERMAN, D.; NORTON, J.;ELLISON, J. Plesiomonas shigeloides and Salmonella sorovar Hartford infections associated with a contaminated water supply. Livingston County, New York. Morbidad and Mortality Weekly Report, v. 47, n. 19, p. 394-396, 1998. 